Pacific Journal of Mathematics

A THEOREM ON BOUNDED ANALYTIC FUNCTIONS 


\section{A THEOREM ON BOUNDED ANALYTIC FUNCTIONS}

\section{Michael C. MOONEY}

The purpose of this paper is to prove the following THEOREM: Let $\phi_{1}, \phi_{2}, \cdots$ be an infinite sequence of functions in $L^{1}([0,2 \pi])$ such that $L(f)=\lim _{n \rightarrow \infty} \int_{0}^{2 \pi} f\left(e^{i \theta}\right) \phi_{n}(\theta) d \theta$ exists for every $f \in H^{\infty}$. Then there is a $\phi \in L^{1}([0,2 \pi])$ such that $\boldsymbol{L}(f)=\int_{0}^{2 \pi} f\left(e^{i \theta}\right) \phi(\theta) d \theta$ for all $f \in H^{\infty}$.

Throughout this paper we will use the following notation and conventions: $D$ will denote the unit disc and $T$ its boundary. In order to save time we will avoid making distinctions between $T$ and $[0,2 \pi]$ if no confusion results. Similarly, it will be convenient to treat elements of $H^{\infty}\left[=H^{\infty}(D)\right.$, the bounded analytic functions on $\left.D\right]$ as though they were the same as those functions on $T$ with which they are naturally identified.

If $w \in D$, the symbol $g_{w}$ will stand for the function $z \rightarrow g(w z)$. $C(T)$ will stand for the usual space of continuous functions on $T . A$ will denote the subspace of $C(T)$ of functions analytically extendable to $D$. $\lambda$ will denote ordinary Lebesgue measure divided by $2 \pi$ and "WLOG" means "without loss of generality".

In their paper [4] Piranian, Shields, and Wells observed that the theorem stated above would imply their result, namely that if $a_{0}, a_{1}, \cdots$ was a sequence of complex constants such that $\lim _{r \rightarrow 1} \sum_{n=0}^{\infty} a_{n} b_{n} r^{n}$ exists for all $f \in H^{\infty}$ [with Taylor coefficients $b_{0}, b_{1}, \cdots$ ], then the $a_{n}$ 's are the the nonnegative Fourier coefficients of an $L^{1}([0,2 \pi])$ function. They also mentioned that our result here was a question raised in [1].

Kahane [3], using a somewhat different method than that in [4] showed that under the hypothesis of our main theorem, there was a $\phi \epsilon$ $L^{1}([0,2 \pi])$ such that the conclusion held for all $f \in A$. He went further to show that the subset of $H^{\infty}$ for which the conclusion held was large in some sense. Our proof here makes use of Kahane's result.

2. Remarks and lemmas. First, given the hypothesis of the main theorem we may assume WLOG that the $\phi_{n}$ 's are uniformly bounded in $L^{1}$ norm. To see why this is so we observe that for each $n, g \rightarrow L_{n}(g)=\int_{T} g \dot{\phi}_{n}$ is a bounded linear functional on $A$. By the uniform boundedness principle, the norms of the $L_{n}$ 's as elements of $A^{*}$ are uniformly bounded, say by $M$. By the Hahn-Banach Theorem, each $L_{n}$ may be extended to an element of $C(T)^{*}$ with norm less than 
M. This extended functional corresponds in the usual way to a Borel measure $\mu_{n}$ on $T$ having variation norm less than $M$. For each $n$, $\mu_{n}-\int \phi_{n}$ is also a finite Borel measure on $T$. Since this measure is orthogonal to $A$, it must be absolutely continuous [by the classical F. and M. Riesz Theorem] and, in turn, so must $\mu_{n}$. Hence we may replace $\phi_{n}$ 's with $d \mu_{n}$ 's if necessary. From here on we assume $\left\|\phi_{n}\right\|_{1} \leqq$ 1 , for all $n$.

Suppose now for purposes of contradiction that there is an $f \in$ $H^{\infty}$ such that $L(f) \neq \int_{T} f \phi$ where $\phi$ is the function referred to in Kahane's result. We may assume WLOG that $\phi \equiv 0$ [simply subtract $\phi$ from $\phi_{n}$ 's beforehand and that $|f|_{\infty}=1$. We also assert WLOG:

LEMma 1. There exists a bounded, increasing function $\beta$ on $T$ such that

$$
\lim _{n \rightarrow \infty} \int_{E}\left|\phi_{n}\right|=\int_{E} d \beta
$$

whenever $E$ is a finite union of closed subintervals of $T$.

Proof. Since all our previous assertions remain valid if the $\phi_{n}$ 's are replaced by an infinite subsequence, we will do this if necessary so that the functions $\int\left|\phi_{n}\right|$ 's converge pointwise on $T$ to a function which we call $\beta$. This construction and the conclusion of the lemma follow from the Helly's Theorem. [See Zygmund [5] IV-4.6-(p. 137).]

We consider the fact that:

$$
\lim _{r \rightarrow 1-} \lim _{n \rightarrow \infty} \int_{T} f_{r} \phi_{n}=0 \neq \lim _{n \rightarrow \infty} \lim _{r \rightarrow 1-} \int_{T} f_{r} \phi_{n}=L(f)
$$

despite the fact that $f_{r}$ 's are uniformly bounded and converge to $f$ in measure. It is reasonable to subspect that in some useful sense of the word that the support of $\int f \phi_{n}$ tends to become concentrated on smaller and smaller sets as $n \rightarrow \infty$.

To be more specific, our plan at this point is to produce a sequence of pairwise disjoint "nice" closed sets $E_{1}, E_{2}, \cdots$ such that $\int_{E_{n}} f \phi_{n}$ tends approximately to $L(f)$ while $\int_{T-E_{n}}\left|f \phi_{n}\right|$ remains uniformly $\stackrel{E_{n}}{<} \varepsilon \ll$ $|L(f)|$. [We will find that it is expedient to replace $f$ with $f-f_{r}$ for some $r$ in order to do this.]

Ultimately we will construct $g \in H^{\infty}$ so that $g$ is approximately $(-1)^{n}$ on $E_{n}$. The function $g f$ [actually we will look at $g \times\left(f-f_{r}\right)$ ] will give us a counterexample to the condition that $L(h)$ exists for all $h \in H^{\infty}$, and hence we will have a contradiction to the assumption 
$L(f) \neq 0$.

Let $\varepsilon_{0}=(1 / 10)|L(f)|$. In order to prove Lemma 2 , it will be desirable to keep the singular part of $\beta$ small, say less than $\varepsilon_{0} / 2$. To be sure of this we can choose a closed subset $E$ of the support of the singular part of $\beta$ such that outside of $E$, the singular part of $\beta$ has variation norm less than $\varepsilon_{0} / 2$.

Let $g$ denote a Rudin-Carleson type function such that $g \in A, g$ is zero on $E$, and $g$ is close to 1 outside some neighborhood of $E$. Such functions were used in both [3] and [4], and a proof of their existence is available in Hoffman [2] p. 80, 81. [See also [2], Notes on p. 95.] If the original $\phi_{n}$ 's are replaced by $g \phi_{n}$ 's, we may proceed as before with our new set of $\phi_{n}$ 's, $\phi, \beta$, etc. The new $d \beta=|g|$ times the old $d \beta$, and hence the singular part of the new $\beta$ will have variation norm less than $\varepsilon_{0} / 2$. This process gives us a new value for $L(f)$, however, and we must be sure that the new value is close enough to the old that our assertion is still valid when the new value of $L(f)$ is used in the expression for $\varepsilon_{0}$. To do this we observe that the functions $f \phi_{n}$ also satisfy the hypothesis of our Theorem [in place of the $\phi_{n}$ 's] and that by Kahane's Theorem, there is a $\psi \in L^{1}([0,2 \pi])$ such that

$$
\lim _{n \rightarrow \infty} \int_{T} h f \phi_{n}=\int_{T} h \psi \text { for all } h \in A .
$$

In particular this is true when $h=g$. Since $\psi$ is absolutely continuous and since we can make $g$ uniformly as close to 1 as we like outside neighborhoods of $E$ taken as small as we like, the new $L(f)=$ $\int_{T} g \psi$ can be taken as close to the old $L(f)=\int_{T} \psi$ as we like. Hence WLOG we may assume that the singular part of $\beta$ has variation norm less than $\varepsilon_{0} / 2$. Let us now choose $\delta>0$ such that

$$
\lambda(E)<\delta \Rightarrow \int_{E} d \beta_{a}<\varepsilon_{0} / 2-\int_{T} d \beta_{S}
$$

where $\beta_{a}$ and $\beta_{s}$ are the absolutely continuous and singular parts of $\beta$ respectively. We note that if $J$ is a finite union of closed intervals, and $\lambda(J)<\delta$, then for $n$ sufficiently large $\int_{J}\left|\phi_{n}\right|<\varepsilon_{0} / 2$.

Choose $r \in(0,1)$ such that $\lambda(F)<\delta$ where

$$
F=\left\{\theta|\theta \in[0,2 \pi],| f\left(e^{i \theta}\right)\left|-f_{r}\left(e^{i \theta}\right)\right| \geqq \varepsilon_{0}\right\} .
$$

Let $G$ be an open subset of $T$ such that $F \subset G$ and $\lambda(G)<\delta$. Since

$$
L\left(f_{r}\right)=0, L(f)=L\left(f-f_{r}\right)=\lim _{n \rightarrow \infty} \int_{G}\left(f-f_{r}\right) \phi_{n}+\lim _{n \rightarrow \infty} \int_{T \rightarrow G}\left(f-f_{r}\right) \phi_{n} .
$$


[We may choose subsequences of the original $\phi_{n}$ 's if necessary in order to guarantee the limits exist.] Now for each $n, \int_{T-G}\left|\left(f-f_{r}\right) \phi_{n}\right| \leqq \varepsilon_{0}$. Hence $\left|\int_{G}\left(f-f_{r}\right) \phi_{n}-L(f)\right|<\varepsilon_{0}$ for all sufficiently large $n$.

LEMma 2. There exists a sequence of sets $E_{1}, E_{2}, \cdots$; a sequence of positive numbers $\delta_{1}, \delta_{2}, \cdots$; and an increasing sequence of positive integers $j_{1}, j_{2}, \cdots$ such that:

(a) Each $E_{n}$ is a finite union of closed intervals.

(b) Let $E_{j}^{\prime}$ denote the closure of the $\delta_{j}$ neighborhood of $E_{j}$. Then $E_{j}^{\prime} \subset G$.

(c) $j \neq k \Rightarrow E_{j}^{\prime} \cap E_{k}^{\prime}=\varnothing . \quad\left[\right.$ Note that this $\Rightarrow \lambda\left(E_{j}\right) \rightarrow 0$, and $\lambda\left(E_{j}^{\prime}\right) \rightarrow$ 0.]

(d) $\int_{G-E_{k}}\left|\phi_{j_{k}}\right|<\varepsilon_{0} / 2$ for $k=1,2, \cdots$.

(e) $\int_{E_{n}}\left(f-f_{r}\right) \phi_{j_{n}} \rightarrow x_{0}$ where $\left|x_{0}-L(f)\right|<2 \varepsilon_{0}$.

Proof. Construction using mathematical induction and the following scheme: After the first $k, E_{j}$ 's, $\delta_{j}$ 's and $j_{n}$ 's are constructed, we pick $j_{k+1}, E_{k+1}$, and $\delta_{k+1}$ in the order.

Using the fact that $\lim _{n \rightarrow \infty} \int_{\cup_{p=1}^{k} E_{p}^{\prime}}\left|\phi_{n}\right|<(1 / 2) \varepsilon_{0}$ [since $\lambda\left(\bigcup_{p=1}^{k} E_{p}^{\prime}\right)<$ $\lambda(G)<\delta]$ and the fact that $\int_{G}\left(f-f_{r}\right) \phi_{n}$ eventually comes within $\varepsilon_{0}$ of $L(f)$, we have that for $j_{k+1}$ sufficiently large: $\int_{\cup_{p=1}^{k} E_{p}^{\prime}}\left|\phi_{j_{k+1}}\right|<(1 / 2) \varepsilon_{0}$ and $\int_{G-\cup_{p=1}^{k} E_{p}^{\prime}}\left(f-f_{r}\right) \phi_{j_{k+1}}$, is within $2 \varepsilon_{0}$ of $L(f)$.

We now choose $E_{k+1}$ inside the open set $G-\bigcup_{p=1}^{k} E_{p}^{\prime}$. Using the absolute continuity of $\phi_{j_{k+1}}$ we can choose $E_{k+1}$ large enough that (d) holds, and that $\int_{E_{k+1}}\left(f-f_{r}\right) \phi_{j_{k+1}}$ is within $2 \varepsilon_{0}$ of $L(f)$.

$\delta_{k+1}$ will now be chosen so that (b) and (c) satisfied. Obviously our construction will satisfy (a), (b), (c), (d). We may choosen an appropriate subsequence if necessary in order that (e) be satisfied as well.

\section{Construction of the counterexample function.}

Lemma 3. Let $E$ be a closed subset of $T, \varepsilon>0$. Then there is a function, $s$, analytic on $D$ such that:

(a) $s$ has positive real part and $|s|_{\infty}<1$

(b) $\theta \in E \Rightarrow\left|s\left(e^{i \theta}\right)-1\right|<\varepsilon$

(c) $\theta \notin E \Longrightarrow\left|s\left(e^{i \theta}\right)\right|<2 \lambda(E) / \varepsilon \cdot \operatorname{dist}(\theta, E)$

(d) $|s(0)|<\lambda(E) / \varepsilon$. 
Proof. Let $U=(1 / \varepsilon) \pi_{E}$ on $T\left[\pi_{E}\right.$ denotes characteristic function for $E$ ]. Let $u$ be the harmonic function on $D$ corresponding to $U$ on the boundary [ $u$ is the integral of $U$ with respect to Poisson's kernel]. Let $v$ be the conjugate harmonic function for $u$ such that $v(0)=0$. Let $g=u+i v$. [ $g$ is analytic on $D$ with positive real part.]

Note that for $\theta \notin E,\left|g\left(e^{i \theta}\right)\right|=\left|v\left(e^{i \theta}\right)\right|$ where

$$
v\left(e^{i \theta}\right)=\frac{1}{2 \pi} \int_{-\pi}^{\pi} u\left(e^{i \phi}\right) \frac{\sin (\theta-\phi)}{1-\cos (\theta-\phi)} d \phi=\frac{1}{2 \pi \varepsilon} \int_{E} \frac{\sin (\theta-\phi)}{1-\cos (\theta-\phi)} d \phi .
$$

The maximum modulus of the function inside the integral occurs when $|\theta-\phi|=\operatorname{dist}(\theta, E)$. In order not to be troubled by awkward trigonometric expressions in the material to follow, we observe by some elementary calculations that $|\sin x| /(1-\cos x)<2 /|x|$ for $|x|<\pi$. Hence we may assert that $\left|v\left(e^{i \theta}\right)\right|<2 \lambda(E) / \varepsilon \cdot \operatorname{dist}(\theta, E)$. Now let

$$
s=g /(1+g)=1-1 /(1+g) .
$$

(a) Since $g$ is of positive real part, the range of $1 /(1+g)$ is contained in the disc $\{z|| z-1 / 2 \mid<1 / 2\}$. So is the range of $s$.

(b) For $\theta \in E, \operatorname{Re}\left(g\left(e^{i \theta}\right)\right)=1 / \varepsilon$ and hence $\operatorname{Re}\left(1+g\left(e^{i \theta}\right)\right)=1+1 / \varepsilon$. This makes $\left|1+g\left(e^{i \theta}\right)\right| \geqq 1+1 / \varepsilon$ and in turn $\left|1 /\left(1+g\left(e^{i \theta}\right)\right)\right| \leqq \varepsilon /(1+\varepsilon)<\varepsilon$ whence $\left|s\left(e^{i \theta}\right)-1\right|=\left|1 /\left(1+g\left(e^{i \theta}\right)\right)\right|<\varepsilon$.

(c) For $\theta \notin E,\left|s\left(e^{i \theta}\right)\right|=\left|g\left(e^{i \theta}\right)\right| /\left|1+g\left(e^{i \theta}\right)\right|$ where

$$
\left|g\left(e^{i \theta}\right)\right|<2 \lambda(E) / \varepsilon \cdot \operatorname{dist}(\theta, E) \text { and }\left|1+g\left(e^{i \theta}\right)\right| \geqq 1
$$

(d) $s(0)=g(0) /(1+g(0))$, where $g(0)=\lambda(E) / \varepsilon$ and the proof is complete.

Construction. Given $\varepsilon_{1}>0, \varepsilon_{2}>0$; a sequence of functions $s_{1}, s_{2}, \cdots$ is to be constructed as follows:

Suppose $s_{1}, s_{2}, \cdots, s_{k}$ have been chosen and that $S_{k}=\sum_{j=1}^{k} s_{j}$ is such that $\left|S_{k}\right|_{\infty}=M_{k}<\infty, s_{k+1}$ will be of the form $c_{k+1} s$ where $c_{k+1}$ is a positive real number and $s$ is related to $E_{n_{k+1}}$ in the same manner that $s$ is related to $E$ in Lemma 3 .

We want $c_{k+1}$ sufficiently large and $\varepsilon$ [in Lemma 3] sufficiently small that:

(a) $\quad \theta \in E_{n_{k+1}} \Rightarrow \varepsilon_{2} \log \left|S_{k+1}\left(e^{i \theta}\right)\right|=(-1)^{k+1}(\pi / 2)(\bmod 2 \pi)-\pi / 2$ within an error of magnitude not more than $\varepsilon_{1}$. Note that we can pick $\varepsilon$ dependent only on $\varepsilon_{1}$ and $\varepsilon_{2}$ [independent of $k+1$ ], and $c_{k+1} \gg M_{k}$ so as to make the ratio between $\left|s_{k+1}+S_{k}\right|$ and $\left|\operatorname{Re}\left(s_{k+1}\right)\right|$ small enough to make $\log \left|S_{k+1}\right|$ close enough to $\log \left(c_{k+1}\right)$ on $E_{n_{k+1}}$ for this purpose. Furthermore, the choice of $c_{k+1}$ depends only on $E_{n_{1}}, E_{n_{2}}, \cdots, E_{n_{k}}$. We wish further to have:

(b) $\theta \in E_{n_{k}}=\varepsilon_{2} \log \left|S_{p}\left(e^{i \theta}\right)\right|=(-1)^{k} \pi / 2(\bmod 2 \pi)-\pi / 2$ within an 
error of magnitude not more than $\varepsilon_{1}$ for all $p>k$. To do this, we use the fact that for $\theta \in E_{n_{k}}, p>k$; then $\operatorname{dist}\left(\theta, E_{n_{p}}\right)>\delta_{n_{k}}$ [independent of $p$-note]. Hence $\left|s_{p}\left(e^{i \theta}\right)\right|<c_{p} \lambda\left(E_{n_{p}}\right) / \varepsilon \cdot \operatorname{dist}\left(\theta, E_{n_{p}}\right)<c_{p} \lambda\left(E_{n_{p}}\right) / \varepsilon \delta_{n_{k}}$. Recall that the choice of $c_{p}$ depends only on $S_{p-1}$ and is independent of $E_{n_{p}}$. Hence we may require that $\lambda\left(E_{n_{p}}\right) \rightarrow 0$ sufficiently rapidly to guarantee that $\sum_{p=k+1} c_{p} \lambda\left(E_{n_{p}}\right) / \varepsilon \delta_{n_{k}}$ is always small enough that (b) is satisfied. The above requirement also guarantees that $\sum_{k=1}^{\infty} c_{k} \lambda\left(E_{n_{k}}\right) / \varepsilon$ converges.

Each $s_{p}$ has positive real part and hence by Harnack's principal the $S_{p}$ 's must either converge to an analytic function, $S$, of positive real part on $D$, or diverge to $\infty$ on $D$. The latter is impossible since each $\left|S_{p}(0)\right|<\sum_{k=1}^{p}\left|s_{k}(0)\right| \leqq \sum_{k=1}^{p} c_{k} \lambda\left(E_{n_{k}}\right) / \varepsilon<\sum_{k=1}^{\infty} c_{k} \lambda\left(E_{n_{k}}\right) / \varepsilon<\infty$. We also note that our requirement in (b) above also guarantees that the $S_{p}$ 's converge absolutely on each $E_{n_{k}}$ and hence we also have: $\theta \in E_{n_{k}} \Rightarrow$ $\varepsilon_{2} \log |S|=(-1)^{k} \pi / 2(\bmod 2 \pi)-\pi / 2$ within an error of magnitude not more than $\varepsilon_{1}$.

Let $g=e^{i \varepsilon_{2} \log S}$. Then $g$ is bounded on $D$ [in fact: $e^{-\varepsilon_{2} \pi / 2}<|g(z)|<$ $e^{\varepsilon_{2} \pi / 2}$ for all $\left.z \in D\right] . \quad \theta \in E_{n_{p}} \Rightarrow \operatorname{argument}\left(g\left(e^{i \theta}\right)\right)=\left((-1)^{p} \pi / 2\right)(\bmod 2 \pi)-$ $\pi / 2+$ error not larger than $\varepsilon_{1}$. This is, given $\varepsilon_{3}>0$ we may choose $\varepsilon_{1}, \varepsilon_{2}$ so that $1-\varepsilon_{3}<|g(z)|<1+\varepsilon_{3}$ for all $z \in D$ and such that $\left|g\left(e^{i \theta}\right)-(-1)^{p}\right|<\varepsilon_{3}$ for all $\theta \in E_{n_{p}}$. Now:

$$
\begin{aligned}
\int_{T} g\left(f-f_{r}\right) \phi_{j_{n_{k}}}= & \int_{E_{n_{k}}} g\left(f-f_{r}\right) \phi_{j_{n_{k}}}+\int_{G-E_{n_{k}}} g\left(f-f_{r}\right) \phi_{j_{n_{k}}} \\
& +\int_{T-G} g\left(f-f_{r}\right) \dot{\phi}_{{j_{n}}_{n_{k}}} .
\end{aligned}
$$

Recalling Lemma 2, we see that the first of these three integrals is within $2 \varepsilon_{0}\left(1+\varepsilon_{3}\right)$ of $(-1)^{p} L(f)$; the second has magnitude less than $\varepsilon_{0}\left(1+\varepsilon_{3}\right)$ [by (d), Lemma 2] and the third also has magnitude less than $\varepsilon_{0}\left(1+\varepsilon_{3}\right)$ [from the way in which $f_{r}$ and $G$ were chosen]. If $\varepsilon_{3}$ is chosen small enough, $\int_{T} g\left(f-f_{r}\right) \phi_{j_{n k}}$ fails to have a limit as $k \rightarrow$ $\infty$ and we have our contradiction.

\section{REFERENCES}

1. L. Brown, A. Shields, and K. Zeller, On absolutely convergent exponential sums, Trans. Amer. Math. Soc., 96 (1960), 162-183.

2. K. Hoffman, Banach spaces of Analytic Functions, Prentice Hall, Englewood Cliffs, N. J., 1962.

3. J. P. Kahane, Another theorem on bounded analytic functions, Proc. Amer. Math. Soc., 18 (1967), 827-831.

4. G. Piranian, A. L. Shields and J. H. Wells, Bounded analytic functions and absolutely continuous measures, Proc. Amer. Math. Soc., 18 (1967), 818-826. 
5. A. Zygmund, Trigonometric Series, 2nd Ed., Vol I, Cambridge Univ. Press, Cambridge, 1959.

Received April 15, 1971 and in revised form February 3, 1972.

Louisiana State UnIVERSITy 



\section{PACIFIC JOURNAL OF MATHEMATICS}

\section{EDITORS}

\author{
H. SAMELSON \\ Stanford University \\ Stanford, California 94305 \\ C. R. HOBBY \\ University of Washington \\ Seattle, Washington 98105
}

\author{
J. DugundJI \\ Department of Mathematics \\ University of Southern California \\ Los Angeles, California 90007
}

\author{
RICHARD ARENS \\ University of California \\ Los Angeles, California 90024
}

\section{ASSOCIATE EDITORS}
E. F. BECKENBACH
B. H. NeumanN
F. WOLF
K. YoSHIDA

\section{SUPPORTING INSTITUTIONS}

\author{
UNIVERSITY OF BRITISH COLUMBIA \\ CALIFORNIA INSTITUTE OF TECHNOLOGY \\ UNIVERSITY OF CALIFORNIA \\ MONTANA STATE UNIVERSITY \\ UNIVERSITY OF NEVADA \\ NEW MEXICO STATE UNIVERSITY \\ OREGON STATE UNIVERSITY \\ UNIVERSITY OF OREGON \\ OSAKA UNIVERSITY
}

\author{
UNIVERSITY OF SOUTHERN CALIFORNIA \\ STANFORD UNIVERSITY \\ UNIVERSITY OF TOKYO \\ UNIVERSITY OF UTAH \\ WASHINGTON STATE UNIVERSITY \\ UNIVERSITY OF WASHINGTON \\ $* * * *$
$*$
AMERICAN MATHEMATICAL SOCIETY
NAVAL WEAPONS CENTER
}

The Supporting Institutions listed above contribute to the cost of publication of this Journal, but they are not owners or publishers and have no responsibility for its content or policies.

Mathematical papers intended for publication in the Pacific Journal of Mathematics should be in typed form or offset-reproduced, (not dittoed), double spaced with large margins. Underline Greek letters in red, German in green, and script in blue. The first paragraph or two must be capable of being used separately as a synopsis of the entire paper. The editorial "we" must not be used in the synopsis, and items of the bibliography should not be cited there unless absolutely necessary, in which case they must be identified by author and Journal, rather than by item number. Manuscripts, in duplicate if possible, may be sent to any one of the four editors. Please classify according to the scheme of Math. Rev. Index to Vol. 39. All other communications to the editors should be addressed to the managing editor, Richard Arens, University of California, Los Angeles, California, 90024.

50 reprints are provided free for each article; additional copies may be obtained at cost in multiples of 50 .

The Pacific Journal of Mathematics is published monthly. Effective with Volume 16 the price per volume (3 numbers) is $\$ 8.00$; single issues, $\$ 3.00$. Special price for current issues to individual faculty members of supporting institutions and to individual members of the American Mathematical Society: $\$ 4.00$ per volume; single issues $\$ 1.50$. Back numbers are available.

Subscriptions, orders for back numbers, and changes of address should be sent to Pacific Journal of Mathematics, 103 Highland Boulevard, Berkeley, California, 94708.

PUBLISHED BY PACIFIC JOURNAL OF MATHEMATICS, A NON-PROFIT CORPORATION

Printed at Kokusai Bunken Insatsusha (International Academic Printing Co., Ltd.), 270, 3-chome Totsuka-cho, Shinjuku-ku, Tokyo 160, Japan. 


\section{Pacific Journal of Mathematics}

\section{Vol. 43, No. 2 \\ April, 1972}

Arne P. Baartz and Gary Glenn Miller, Souslin's conjecture as a problem on the real line....................................... 277

Joseph Barback, On solutions in the regressive isols ............... 283

Barry H. Dayton, Homotopy and algebraic K-theory ................ 297

William Richard Derrick, Weighted convergence in length ............ 307

M. V. Deshpande and N. E. Joshi, Collectively compact and semi-compact sets of linear operators in topological vector spaces ............. 317

Samuel Ebenstein, Some $H^{p}$ spaces which are uncomplemented in $L^{p} \ldots . .327$

David Fremlin, On the completion of locally solid vector lattices ......... 341

Herbert Paul Halpern, Essential central spectrum and range for elements of

a von Neumann algebra............................... 349

G. D. Johnson, Superadditivity intervals and Boas' test ............. 381

Norman Lloyd Johnson, Derivation in infinite planes . . . . . . . . . . . 387

V. M. Klassen, The disappearing closed set property .............. 403

B. Kuttner and B. N. Sahney, On the absolute matrix summability of Fourier series ........................................... 407

George Maxwell, Algebras of normal matrices................... 421

Kelly Denis McKennon, Multipliers of type $(p, p) \ldots \ldots \ldots \ldots \ldots \ldots . . \ldots 29$

James Miller, Sequences of quasi-subordinate functions ............. 437

Leonhard Miller, The Hasse-Witt-matrix of special projective varieties ..... 443

Michael Cannon Mooney, A theorem on bounded analytic functions ...... 457

M. Ann Piech, Differential equations on abstract Wiener space .......... 465

Robert Piziak, Sesquilinear forms in infinite dimensions ............. 475

Muril Lynn Robertson, The equation $y^{\prime}(t)=F(t, y(g(t))) \ldots \ldots \ldots \ldots .483$

Leland Edward Rogers, Continua in which only semi-aposyndetic

subcontinua separate ............................... 493

Linda Preiss Rothschild, Bi-invariant pseudo-local operators on Lie

groups ...................................... 503

Raymond Earl Smithson and L. E. Ward, The fixed point property for

arcwise connected spaces: a correction ...................... 511

Linda Ruth Sons, Zeros of sums of series with Hadamard gaps .......... 515

Arne Stray, Interpolation sets for uniform algebras............... 525

Alessandro Figà-Talamanca and John Frederick Price, Applications of random Fourier series over compact groups to Fourier multipliers .. 